\title{
CONSTRICTIVE PERICARDITIS
}

\author{
BY \\ WILLIAM EVANS AND FREDERIC JACKSON
}

From the Cardiac Department of the London Hospital

Received June 15, 1951

Some 23 years have passed since the suggestion was first made that the symptoms of constrictive pericarditis might yield to surgical treatment (Volhard and Schmieden, 1928). This interval has ripened judgment on the effects of this therapeutic procedure, and it is now opportune to pass opinion on the value of the operation and on other aspects of the condition; especially its ætiology, distinctive physical signs, and the meaning of certain cardiographic and cardioscopic appearances. These are described in the light of our experience with 30 patients who have undergone surgical treatment.

The series was made up of 26 males and 4 females. The youngest patient was 11 years of age and the oldest 63; there were 6 in the second decade, 7 in the third, 3 in the fourth, 6 in the fifth, 7 in the sixth, and 1 was over sixty years of age.

\section{ÆTiology and Pathology}

White (1935) and Harrison and White (1942), reporting on the progress of 1500 patients with rheumatic heart disease, found among them no instance of constrictive pericarditis. In one of our patients mitral stenosis was found side by side with constrictive pericarditis (Jackson, 1950). This one example does not justify the view that constrictive pericarditis is a rheumatic condition, and we have regarded the association as fortuitous in this patient. Apart from the rarity of mitral stenosis in constrictive pericarditis-one reported case and one in our series-the relative sex incidence of 26 males and 4 females, opposes the suggestion that the pericardial condition may have a rheumatic origin in that mitral stenosis is much commoner in women. A history of rheumatic fever was obtained in two patients only. Acute pericarditis occurred in five, and in four of them it preceded the development of signs of constriction by only a matter of months; in the fifth the attack of pericarditis happened 23 years before.

We bring evidence from our cases to support the view that constrictive pericarditis is the outcome of a tuberculous infection. In four there was active tuberculosis in a close relative and in a fifth, in the family where the patient lodged; in a sixth case the patient's father had a deformed spine from Pott's disease. Involvement of the pleura was common and four gave a history of pleurisy, though in none was it proved bacteriologically to be tuberculous in nature; there was a large effusion on the right side in four cases. Pleural thickening was met with on the right side in seven, ' on the left in one, and on both sides in six. Evidence of tuberculosis was found in four patients who did not undergo operative treatment and for that reason are not included in this series; in one there was fibrosis of lungs and in another active pulmonary tuberculosis; tuberculous glands were confirmed at biopsy in a third, and in a fourth there was tuberculous infection of the elbow joint. In another three patients, treated surgically and therefore included in this series, there was substantial evidence that tuberculosis had caused the infection: in one dissemination of tuberculosis in the lungs and liver, and in another general dissemination, had taken place after the operation; in a third tubercle bacilli were isolated from the pericardial debris removed at operation. 
At operation the heart was found encased in a dense and fibrous pericardium which was often as much as $1.0 \mathrm{~cm}$. thick. Both layers were affected, so that the pericardial space was obliterated and fibrous strands often invaded the myocardium making pericardial stripping difficult in such cases. Areas of calcification were common and occurred in 23 of our 30 cases, and especially in the A-V groove. Localized collections of a creamy-white caseous material were often met with in the deeper layers of the pericardium.

Microscopic examination did not supply the ætiology of the disease in most cases and guineapig inoculation with the caseous material idid not produce the infection. Fibro-caseous tuberculosis of the pericardium was present in two patients, and two others developed miliary tuberculosis though no direct evidence of the infection was obtained from examination of the pericardium. The dense fibrosis with hyalinization, and the sparsity of cells and small vessels is quite unlike the pericardial thickening of rheumatic heart disease (Armstrong, 1940), and we are in agreement with Andrews et al. (1948) that tuberculosis is the actual cause of the disease.

\section{SyMPTOMATOLOGY}

Breathlessness on exertion proved to be the earliest and commonest complaint and it was present in all but two of our patients; in these two the condition was discovered fortuitously, one on re-enlistment in the army and the other during an illness that proved to be glandular fever. Dyspnca at rest was met with in five patients all of whom had gross ascites. In none was there pulmonary congestion radiologically. Although breathlessness is such a common symptom, it differs from the dyspnœa of pulmonary congestion in heart failure. The symptom portrays an inability to walk apace, but disappears at the moment of halting unless respiration is embarrassed by a high diaphragm from an abdomen distended by ascites. One patient with his hand held at the umbilicus said, "I am all right from here up and I am all wrong from here down," meaning that he was not breathless, but that he was incapacitated by his ascites and œdema of the ankles. Instead of breathlessness we propose the term, restricted ambulation, to describe this common symptom of constrictive pericarditis.

Fulness or swelling of the abdomen was a prominent symptom in two-thirds of the patients; it was often an early complaint, and was caused by a distehded liver often combined with a varying amount of ascites. Edema of the ankles had been noticed by the same number of patients, and although it appeared earlier than the abdominal swelling in a few, it was commoner to find it developing some time after the ascites, and it was always less noticeable.

Among other symptoms complained of were pain in the left chest (but it was never suggestive of cardiac pain), swelling of the face, tightness of the neck, tiredness, and cough.

\section{Physical Signs}

Many of the objective symptoms of constrictive pericarditis are found in patients with heart failure, especially when it involves primarily the right side of the heart, and this accounts for many instances of pericardial disease that continue to go unrecognized. In order to emphasize this similarity and point particularly to the signs that lead to an earlier recognition of the condition, we have arranged them in three divisions, the first to include signs common both to constrictive pericarditis and right heart failure, the second dealing with signs unlike those in heart failure, and the third describing physical signs distinctive of constrictive pericarditis.

\section{Signs Common to Right Heart Failure}

Examination of the pulse in constrictive pericarditis found it similar to that in failure of the right heart. Thus, it was often noticeably small; in 17 patients the pulse pressure was $30 \mathrm{~mm}$. or less and once it was $15 \mathrm{~mm}$. The highest pulse pressure recorded was $50 \mathrm{~mm}$. so that a large pulse was not once found in 30 patients. Lowering of the pulse pressure during inspiration (paradoxical pulse) was not a common finding and we agree with Paul, Castleman, and White (1948), who met with this in rather less than half their cases, that it is not a helpful sign in diagnosis. 
The blood pressure was never raised in our cases. In only one was the systolic level higher than $135 \mathrm{~mm}$.; in 23 the systolic pressure was $120 \mathrm{~mm}$. or less and in 11 it was under $100 \mathrm{~mm}$.

In 14 of the 30 patients the pulse was regular and normal sinus rhythm lasted throughout the period of observation undisturbed by the injury caused to the heart muscle by surgical interference. Auricular fibrillation was present in 13 patients when they were first examined, and it persisted in each case irrespective of any clinical improvement that followed the operation. Fibrillation was commoner in the older group, so that although it was met with in two before the age of 30 , ten patients were over the age of 45 years. In three others auricular fibrillation set in after the operation; in two it was paroxysmal, alternating with paroxysmal tachycardia in one, and preceding established fibrillation in the other. In five of the seven patients with fibrillation examined before digitalis was given, the ventricular rate was relatively slow (70 to 90 a minute) and in five of the six cases already taking digitalis it was slower (50 to 70 a minute). A more rapid ventricular rate (over 120

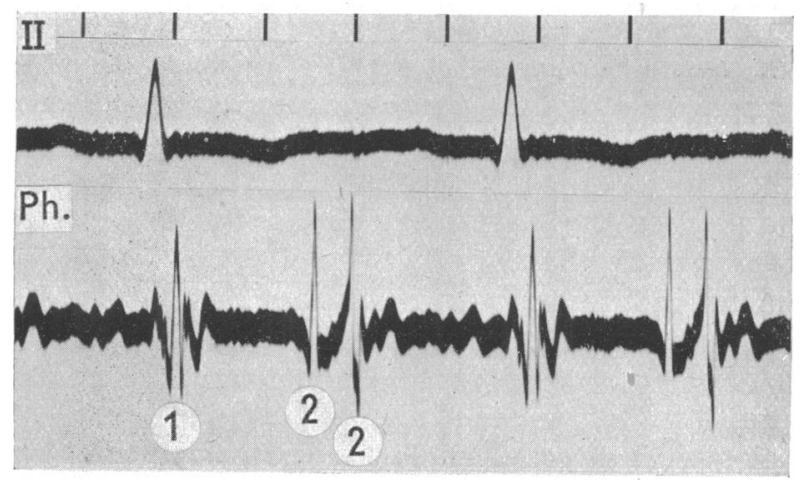

Fig. 1.-Constrictive pericarditis. . Phonocardiogram shows splitting of second heart sound. Second or pulmonary component has greater amplitude than first or aortic component. Time interval here and in other figures is $0 \cdot 2 \mathrm{sec}$.

FIG. 2.-Constrictive pericarditis. Phonocardiogram showing triple heart rhythm from addition of the third heart sound.

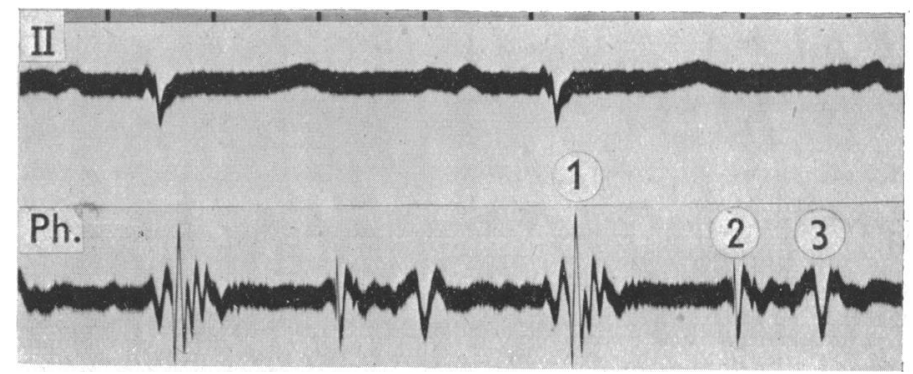

a minute) was met with in four patients, two of them with established and two with paroxysmal fibrillation. In one patient the onset of fibrillation more than two years after the operation had brought no symptoms, and the heart rate was 80 a minute in the absence of digitalis therapy. Conditions that might determine the presence of auricular fibrillation such as cardiac enlargement, heart failure, or excessive pericardial calcification, were looked for, but apart from age, none appeared to favour the onset of the arrhythmia. Extrasystoles, occurring in three patients, were considered to be fortuitous, and no other form of arrhythmia was met with.

When patients with constrictive pericarditis were first selected for surgical treatment, an adventitious sound in early diastole was found commonly. At first, clinical auscultation interpreted this as triple heart rhythm from addition of the third heart sound, although it was mentioned at the time in most of them that the gap between the second and subsequent sound was shorter than the one customary for this form of triple rhythm. When phonocardiography was applied to this particular problem it showed that splitting of the second heart sound explained those instances where 
the extra sound followed close on the second, while in patients exhibiting the cadence typical of triple rhythm the test confirmed that addition of the third heart sound was the cause. When subsequent clinical examination was fortified by this newer knowledge of the auscultatory findings, differentiation of the two groups no longer gave rise to difficulty. Indeed, it may now be emphasized that, since the phonocardiogram has identified the adventitious sound in both groups, the test need not become routine in the investigation of a patient with constrictive pericarditis, unless there is difficulty in distinguishing the splitting of the second sound from a sound in late systole.

Auscultation in the mitral area and along a line joining this to the xiphisternum, found an adventitious sound in 27 out of 30 cases. In 17 this was found to be a splitting of the second heart sound (Fig. 1) and in 10, addition of the third heart sound had initiated a triple heart rhythm (Fig. 2). Only three times did the two auscultatory signs appear side by side. Triple rhythm was not more likely to be present when physical signs like venous and liver distensions and ascites were prominent or had been present for some time.

A phonocardiogram was recorded in 26 patients and in 18 it was done both before and after the operation. In 22 cases in which splitting of the second heart sound was present in the tracing the interval between the aortic and pulmonary components of the sound varied from 0.04 to $0 \cdot 10 \mathrm{sec}$. and the average was $0.07 \mathrm{sec}$. The interval was a little longer than that which was found in a series of ten healthy subjects all showing splitting of the second sound in the pulmonary area and where an average value of $0.04 \mathrm{sec}$. was obtained during expiration and $0.06 \mathrm{sec}$. during inspiration (Leatham and Towers, 1951).

The auscultatory sign in healthy subjects differed in three ways from that heard in patients with constrictive pericarditis; first, the pulmonary component of the second heart sound in the latter group was accentuated and this made it audible some distance from the pulmonary area (where it is heard in health) as far as a line adjoining the mitral auscultatory area to the xiphisternum. Secondly, this accentuated pulmonary sound occurred alongside an easily audible aortic component, and thirdly the interval between the two moieties was sometimes a little prolonged.

In 14 patients where a third heart sound was recorded in the tracing, although it had been audible as triple rhythm in only 10 , the interval between the second and third heart sounds varied from $0 \cdot 10$ to $0.22 \mathrm{sec}$. with an average value of $0.17 \mathrm{sec}$; here, too, the interval between the sounds did not differ significantly from the value of $0.19 \mathrm{sec}$. found in a healthy series (Evans, 1943). It was common for these two auscultatory signs to disappear after a successful operation and we came to recognize the value of this in foretelling favourable progress in individual patients. In the earlier cases where the operative approach had been to the left of the sternum and portions of the rib had been removed so that the heart was in close proximity to the chest piece of the stethoscope, a third heart sound, even though physiological, was easily heard.

An incidental murmur in mid-systole was recorded in three patients, but in a fourth who had mitral stenosis as well, a murmur filled systole and another occupied mid-diastole.

Cyanosis, usually seen in the ears, nose, lips, and fingers, was present in half the cases, and was more conspicuous in those patients in whom the condition was known to have produced symptoms for two or more years. It was absent in the early cases and this should never by itself oppose a diagnosis of constrictive pericarditis.

Distension of the neck veins is a constant physical sign in constrictive pericarditis and it was met with in each of our cases. In 21 where the venous pressure was measured it proved to be under $10 \mathrm{~cm}$. of saline in three, between 10 and $20 \mathrm{~cm}$. in nine, and over $20 \mathrm{~cm}$. in nine. Pulsation of the veins was often observed, but in the majority of patients this was not obvious. Since dyspnœa at rest is uncommon in constrictive pericarditis, the presence of distended neck veins in a patient who is able to lie comfortably in the recumbent posture is a characteristic feature of the disease.

Hepatic enlargement was present in each of the 30 patients, and this physical sign ranks with distended veins as a valuable aid to diagnosis; indeed, if these two signs are missing, the diagnosis of constrictive pericarditis should not be entertained. The degree of liver enlargement depends on the severity and the duration of the illness. In the early cases with mild complaints the liver was 
easily felt below the right costal margin, while in those with more prominent symptoms it reached to the level of the umbilicus or lower, and in this event ascites was invariably present. The edge of the liver was always firm or even hard and smooth, and as a rule not tender. In spite of the common incidence of considerable hepatic enlargement, jaundice was never met with.

Ascites was present in 16 cases and in many of these it had been a persistent and troublesome complication up to the time of preparation for operation. It was conspicuous in three of the five patients who have died since the operation and remained or returned in three in whom surgery failed to produce any benefit.

EEdema of the ankles was present in 20 patients, never gross and often slight, even though there was great ascites. Swelling of the face occurred in five patients and in one of these there was no swelling elsewhere.

\section{Signs Dissimilar from those in Right Heart Failure}

Pulmonary crepitations were absent on auscultation except in those where the lung showed fibrosis, probably tuberculous in origin. Further, pulmonary congestion was not found on cardioscopy. Absence of such pulmonary signs in a patient thought to have heart failure should turn attention to the diagnosis of pericardial disease.

Evidence of cardiac enlargement was never present on clinical examination and the cardiac impulse was usually quiet and often absent; the apex beat when it could be located was never displaced outwards.

Unlike most instances of right heart failure constrictive pericarditis does not give rise to significant murmurs. Indeed, should a case exhibit an obvious murmur a diagnosis of the pericardial lesion is unlikely to be the true one. In our series three patients had an immaterial midsystolic murmur and a fourth showed pan-systolic and mid-diastolic murmurs from associated mitral stenosis.

Another difference between the two clinical states lies in the relative preponderance of certain signs. Thus, in constrictive pericarditis ascites may be prominent and œdema of the ankles minimal or absent, while the reverse is true of right heart failure. Again, distension of neck veins and enlargement of the liver are physical signs more prominent in the former condition and at an earlier stage than in the latter.

\section{Distinctive Physical Signs}

Although some of the objective physical signs in constrictive pericarditis are common to other conditions, occurring as they do in the absence of orthodox breathlessness, they are distinctive. Nonetheless, when the condition is suspected on clinical grounds confirmation is obtained from electrocardiographic and radiological examination; occasionally liver biopsy is desirable.

\section{The Electrocardiogram}

The electrocardiogram is a noteworthy test in any patient suspected of pericardial disease. The tracing is reminiscent of that found in cardiac infarction for the changes in both conditions affect the S-T segment early in the illness, and later they give way to a deformity of the $T$ waves. In constrictive pericarditis, a chronic process, changes in the $T$ wave preponderate although the tracing shows other characteristic faults which will be described first.

It has already been mentioned that auricular fibrillation is common in constrictive pericarditis, being present in more than one-third of the cases, and especially occurring in the older patient. The ventricular rate in such patients was not rapid as a rule even in the absence of digitalis therapy. The arrhythmia was not once annulled by the operation. In one instance there was paroxysmal tachycardia, and extrasytoles were found in three cases. The voltage of the curve was seldom low and as a rule it was normal. Exaggerated $Q$ waves were never present. The S-T segment was never abnormal except under the influence of digitalis, but the $S$ wave in lead I was as large as the $R$ wave in 16 of the 30 cases. 


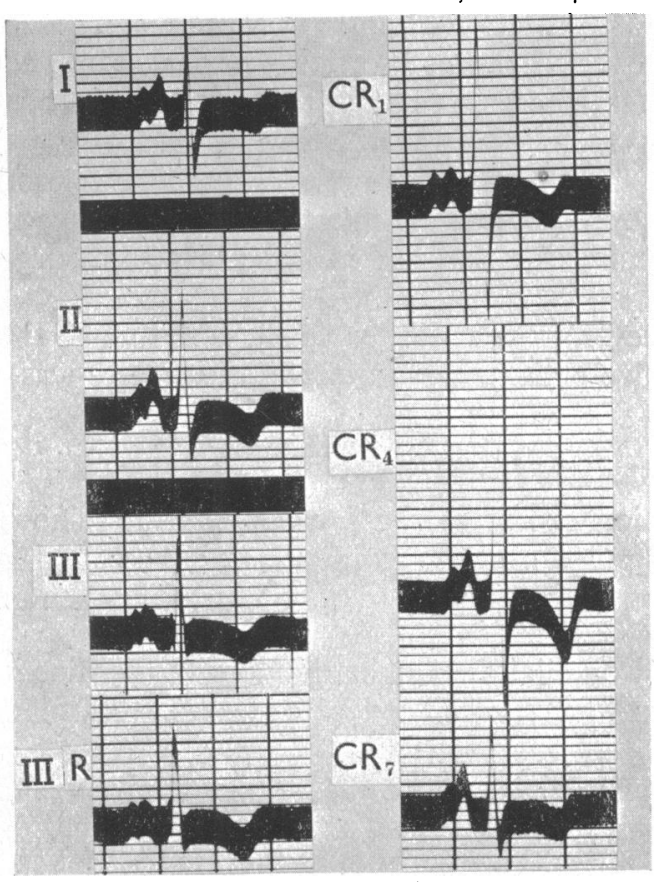

FIG. 3.-Constrictive pericarditis. Notching of $\mathbf{P}$ waves noticeable in limb and chest leads. Inversion of $\mathrm{T}$ waves in all leads.

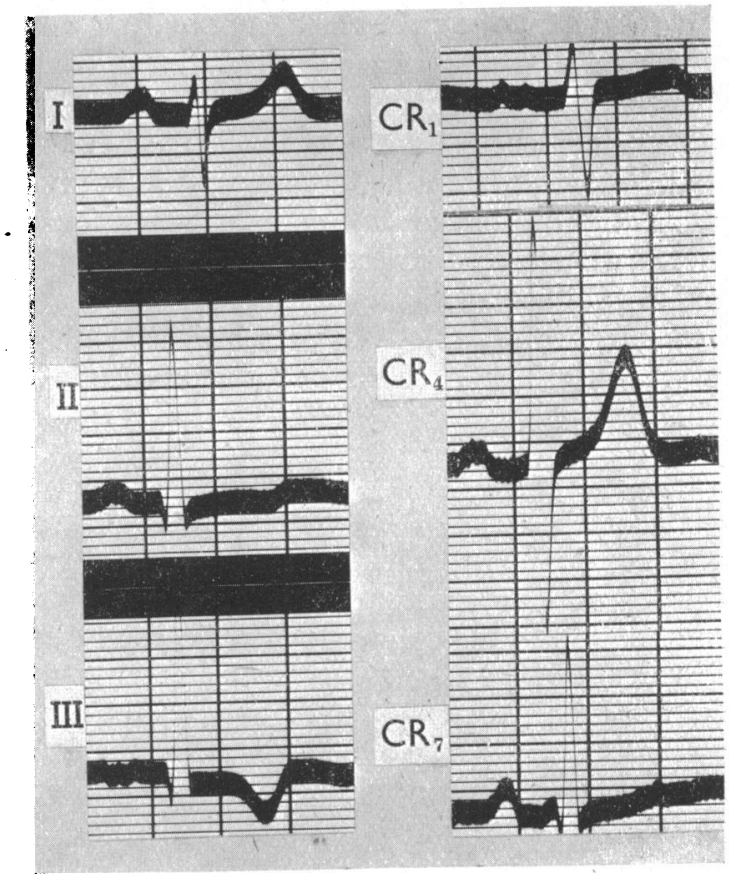

FIG. 4.-Constrictive pericarditis. Inversion of $\mathrm{T}$ wave in leads II and III; $T$ very low in CR7. $\mathbf{P}$ wave broad and bifid in some leads.

The $P$ wave was normal or conventional in only two instances amongst the 17 patients who showed a normal or sinus rhythm. In the remaining 13 cases with auricular fibrillation the $P$ waves had given way to $f$ waves which were in no way distinctive. The characteristic deformity of the $\mathbf{P}$ wave was a notching and often the first peak was lower than the second so that the wave portrayed a shelf or a step (Evans, 1945). This notching of the $P$ wave might be seen in any or in all limb and chest leads (Fig. 3 and 5). So common has been this cardiographic sign that we have come to regard its presence as supporting the diagnosis of pericardial disease, and proving particularly helpful in those cases where the characteristic $T$ wave inversion does not happen to be a feature of the cardiogram.

The $T$ wave, with one exception, was low, flat, or inverted in all the 30 cases; in 11 the $T$ deformity was not gross either in extent or in distribution amongst the leads which included the three chest leads, CR1, CR4, and CR7. The incidence of $T$ wave deformity in the various leads naturally depended on the distribution of the pericardial thickening. Thus, when it was disposed for the greater part postero-laterally the T was inverted in leads II, III, and CR7 (Fig. 4). It was common for inversion of the $T$ wave in CR4 to be added to such changes and sometimes the $T$ was inverted in lead I as well (Fig. 6). While the extent of the pericardial disease was reflected in the number of leads affected, the degree of $T$ wave inversion told of the penetration of the pericardial infection into the myocardium. This was tested as a means of predicting the difficulty met with in stripping the thickened pericardium from the heart; thus, in 10 out of 11 cases in which the changes in the $T$ wave were of a light character the pericardium peeled easily from the heart at operation, compared with the more difficult task in patients who showed deep $T$ wave inversion.

When the post-operative cardiogram was compared with the one recorded before operation it was usually found unchanged and it caused no surprise that sometimes the changes were exaggerated as a result of the damage caused during the pericardial stripping. In eight patients the cardiogram had improved after the operation and the lowered $\mathrm{T}$ wave had moved upwards. 


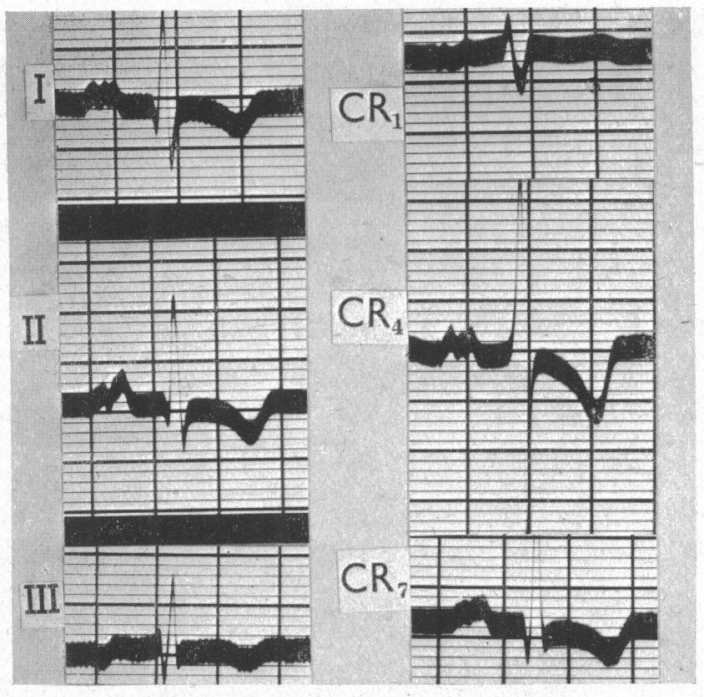

FIG. 5.-Constrictive pericarditis. Inversion of T wave in leads I, II, III, CR4, and CR7. Notching of $\mathbf{P}$ waves.

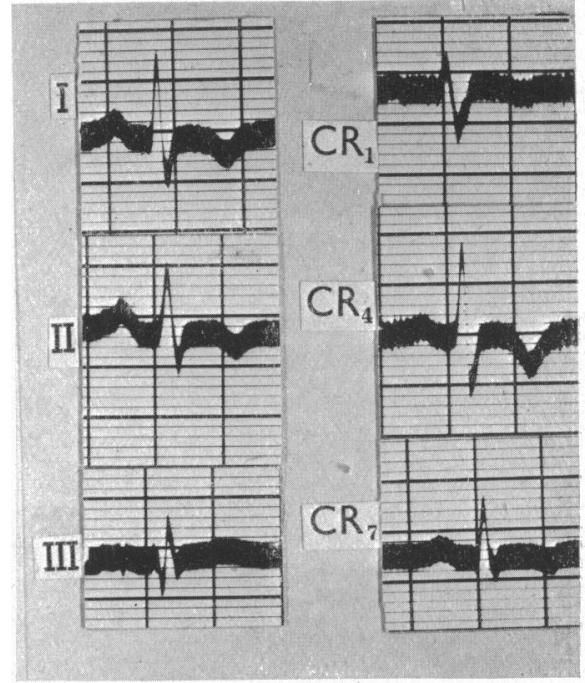

FIG. 6.-Constrictive pericarditis. Inversion of $T$ wave in leads I, II, CR1, CR4, and CR7. $P$ wave notched in lead II.

\section{Radiology}

As an ancillary test in the diagnosis of constrictive pericarditis, radiology of the heart is indispensible, and it should always find a place in the investigation of a patient suspected of this condition. It will usually disclose signs that confirm the presence of constrictive pericarditis and these concern pulsation, size and shape of the cardiac silhouette, a characteristic esophagram, pericardial calcification, and pulmonary changes.

Alteration in cardiac pulsation did not help materially in diagnosis, although it was diminished in many. In one patient in whom the constrictive pericarditis involved the waist of the heart, more than ordinary pulsation presented at the border of the left ventricle. Naturally the distribution of the quiet areas varied according to the location of the pericardial thickening, and their importance lies in the diligent search, which such a finding should promote, of the cardiac border for calcification. In a smaller way it may prove useful in guiding the surgeon to the place where stripping of the pericardium will prove most difficult. The radiogram of constrictive pericarditis when the heart pulsation is subdued may show a sharp outline or stencilled appearance of the cardiac silhouette, although the effect is not as noticeable nor as generalized as in the case of pericardial effusion. After a successful operation exaggerated pulsation was seen in the portion of the heart that had herniated through the pericardial opening, and this showed to best advantage in the right oblique position (Fig. 7).

Size and Shape of the Heart. Although constrictive pericarditis does not produce frank enlargement of the heart with obvious hypertrophy of its walls (Parkinson, 1936; Parsons-Smith, 1948) it is common to find an increase of the cardiac silhouette at cardioscopy. Thus, the shadow was greater than normal in 21 of the 30 patients. This apparent enlargement was slight or moderate (Fig. 8) in 17, and it was greater (Fig. 9) in four; in none was it very conspicuous. Whenever the size of the heart shadow was increased, the effect of a raised diaphragm from a greatly distended liver, commonly associated with much ascites, could not be estimated accurately, although it was likely that the distortion it produced was considerable. In four cases examined at necropsy the weight of the heart was slightly in excess of the average normal, and in one pulmonary embolism some eight hours before death had caused much dilatation. The weight of the heart, however, 


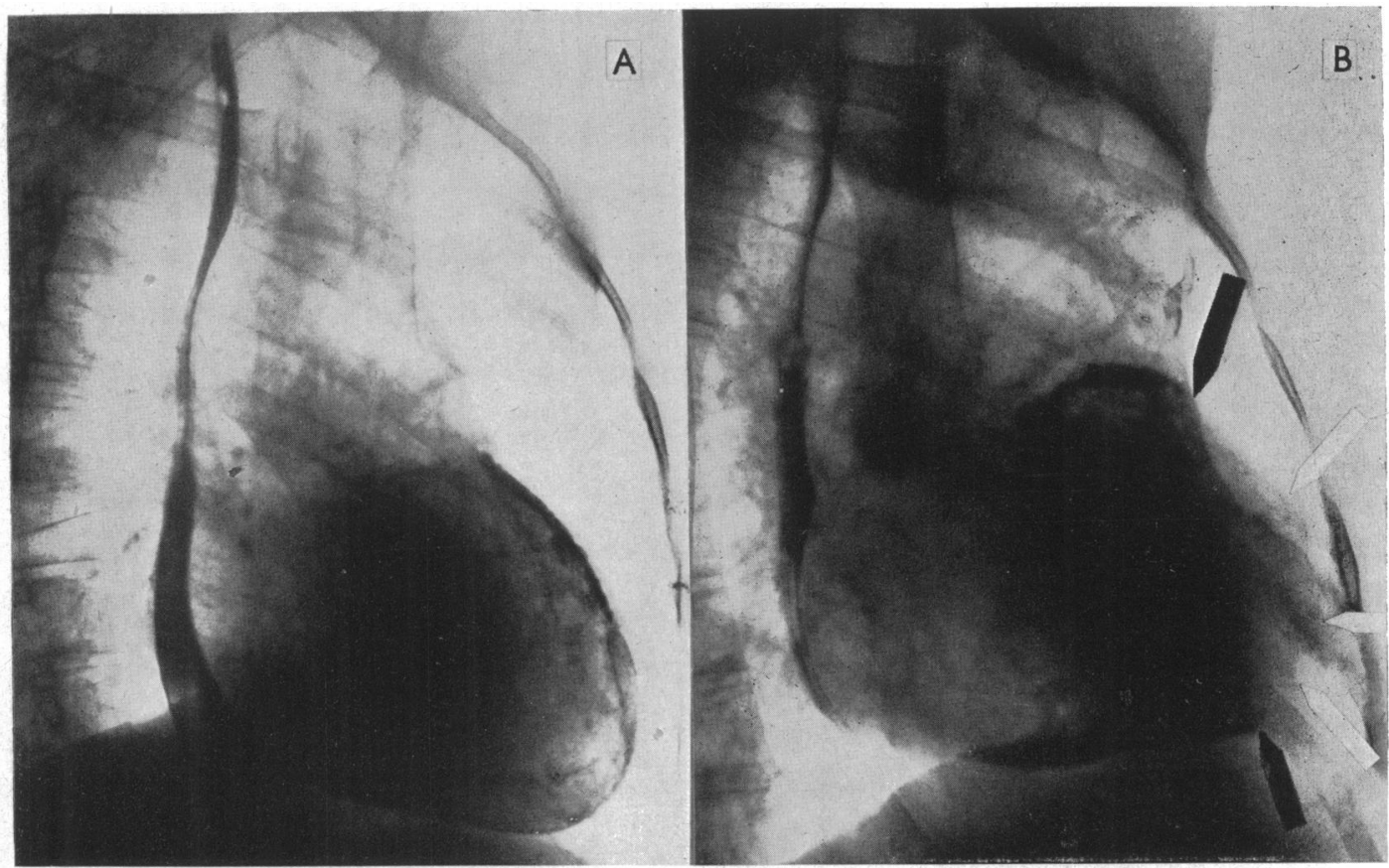

FIG. 7.-Constrictive pericarditis. Teleradiogram R.A.O. (A) Before operation the heart is seen encased by calcium. (B) After operation the heart (white arrows) is seen herniating through opening (black arrows) in calcified pericardium.

was fallacious because it was found impossible to denude the heart wholly of the closely adherent thickened pericardium and this added materially to its true weight.

Whenever constrictive pericarditis had produced much distension of the liver and ascites, the raised diaphragm produced a squat heart shadow with prominence in the region of the left ventricle and more especially of the right side. Even in the absence of this upward displacement, the angle formed by the vascular pedicle and the right auricle was often filled in (Fig. 8 and 10, and Kerley, 1948), causing greater prominence of the right border of the heart. Such prominence was seen in 17 of our patients, while the cardiovascular angle was obscured in 21 , in 7 of whom there was no cardiac enlargement. Distension of the superior vena cava was observed in 16 cases.

The OEsophagram. Escape of the left auricle in constrictive pericarditis produces a characteristic picture during a barium swallow in the right oblique position. The left auricular impression in this view is deep (Fig. 11) and closely resembles the change seen in mitral stenosis. In only seven was this radiological effect missing and we have come to regard it as a valuable sign. Although the exaggerated left auricular impression was often somewhat taller than that found in mitral stenosis, this could not by itself decide the diagnosis. The most characteristic distinguishing feature of the csophagram of constrictive pericarditis was the presence of a relatively clear area between the osophageal stream and the denser part of the cardiac shadow, whereas in mitral stenosis these two structures usually lay contiguous one with the other. This difference is explained by the displaced undistended left auricle in constrictive pericarditis and by the disterided left auricle in mitral stenosis. Naturally, the diagnosis on this premise gains when the auricular impression is a prominent feature of the case. In one patient this clear area was absent and the dense cardiac shadow reached the barium stream as in mitral stenosis; it became known later that in this instance mitral stenosis was present alongside constrictive pericarditis (Jackson, 1950).

Pericardial Calcificaticn. The presence of calcium in the pericardium, visible on radiological 


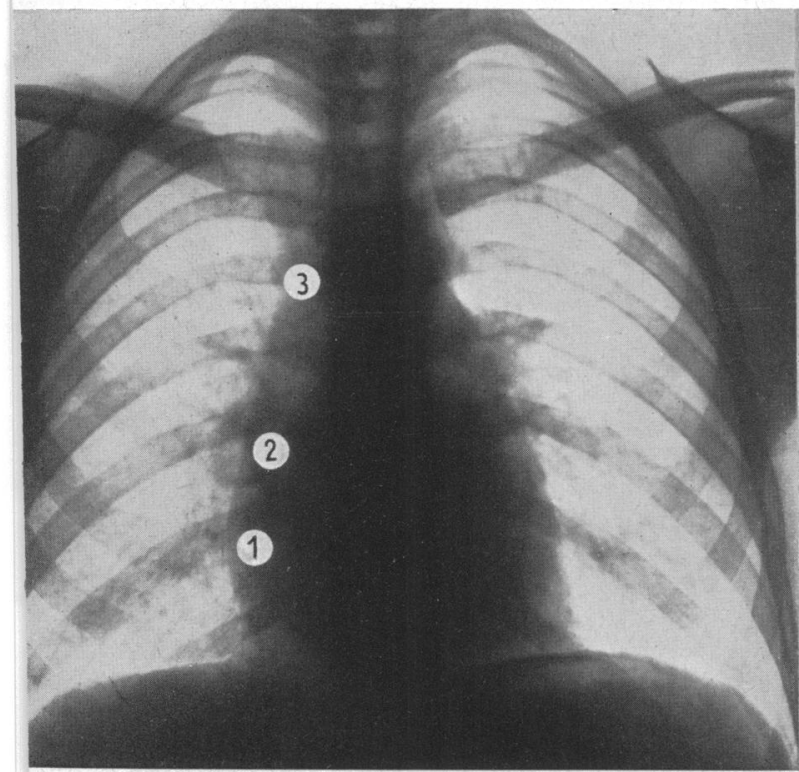

FIG. 8.-Constrictive pericarditis. Slight enlargement of cardiac shadow especially at right auricular border (1). Filling of right cardiovascular angle (2). Prominence of superior vena cava (3).

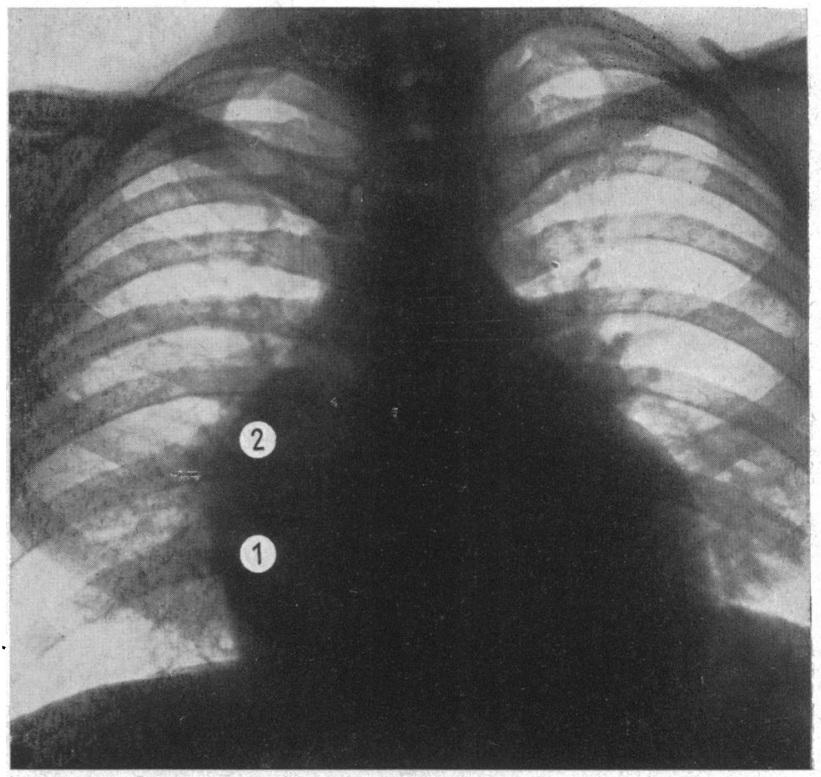

FIG. 9.-Constrictive pericarditis. Considerable enlargement of cardiac shadow where chest is shallow from elevation of diaphragm due to great ascites. Special prominence of right auricle (1), and filling in of right cardiovascular angle (2).

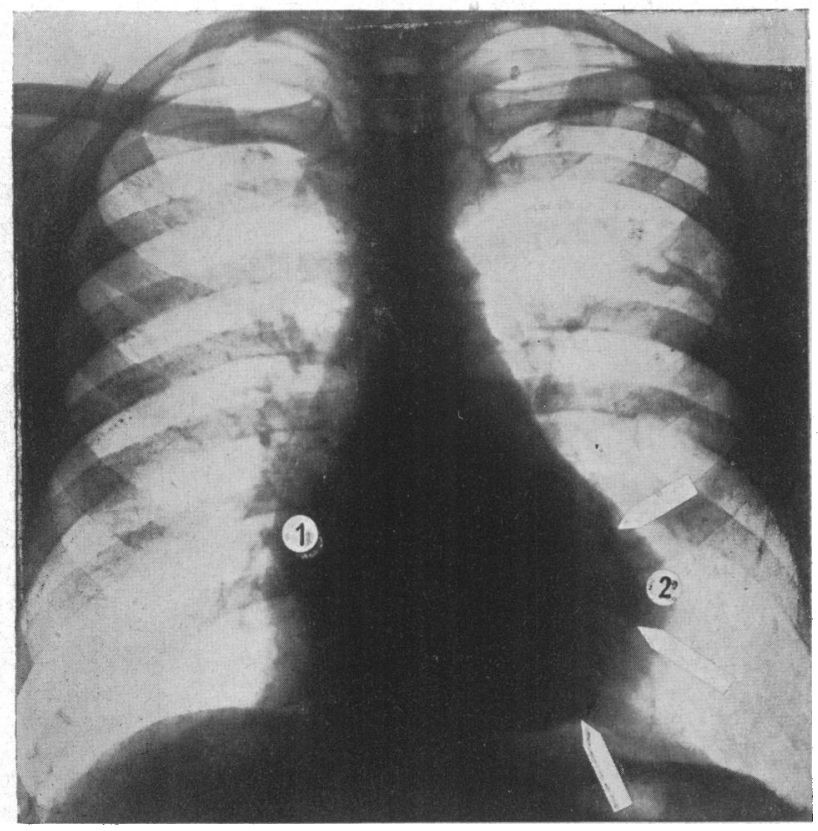

FIG. 10.-Constrictive pericarditis. Filling in of right cardiovascular angle (above 1). Calcium ring (arrows) is within left ventricular border (2) itself displaced to left from escape of heart after operation.

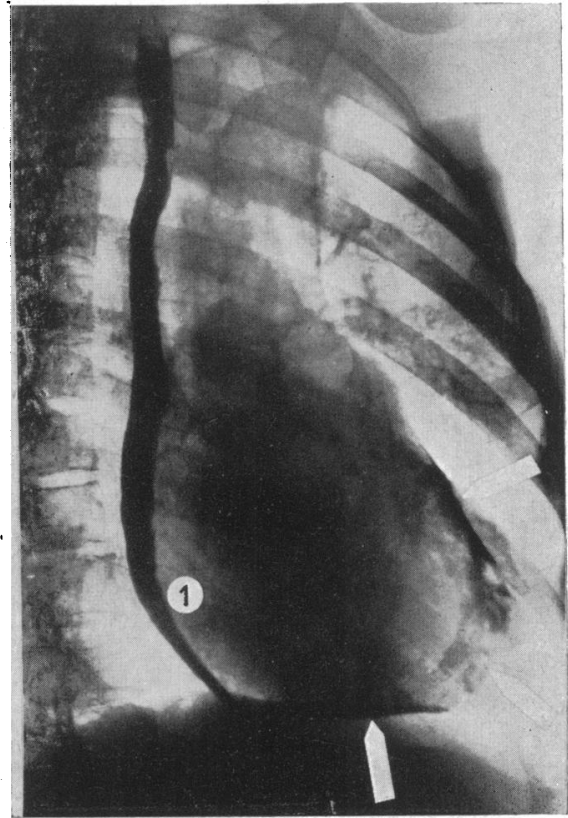

FIG. 11.-Constrictive pericarditis. R.A.O. position. Prominence of left auricular impression (1). Barium stream separated from denser shadow of heart by light zone. Rim of calcium (arrows). 
examination, provides valuable evidence of constrictive pericarditis, and for this reason it should be sought diligently during cardioscopy. First, it should be looked for specially in those areas where cardiac pulsation is most subdued, and if missed during cardioscopy it means that the examination has been carried out without searching purposefully for this change. Calcification was present in 21 and absent in 9 of our cases. In 19 the calcium appeared as an incomplete ring, an appearance created by viewing the calcified pericardium end on. During screening in the anterior position a dense strip may be detected first at the left ventricular border (Fig. 12), and in this event attention should be turned next to the inferior border where it is seen like a saucer upon which the heart appears to rest (Fig. 13); the patient should then be examined in the left oblique position where the calcification is usually seen to best advantage appearing as a cup holding the heart (Fig. 14).

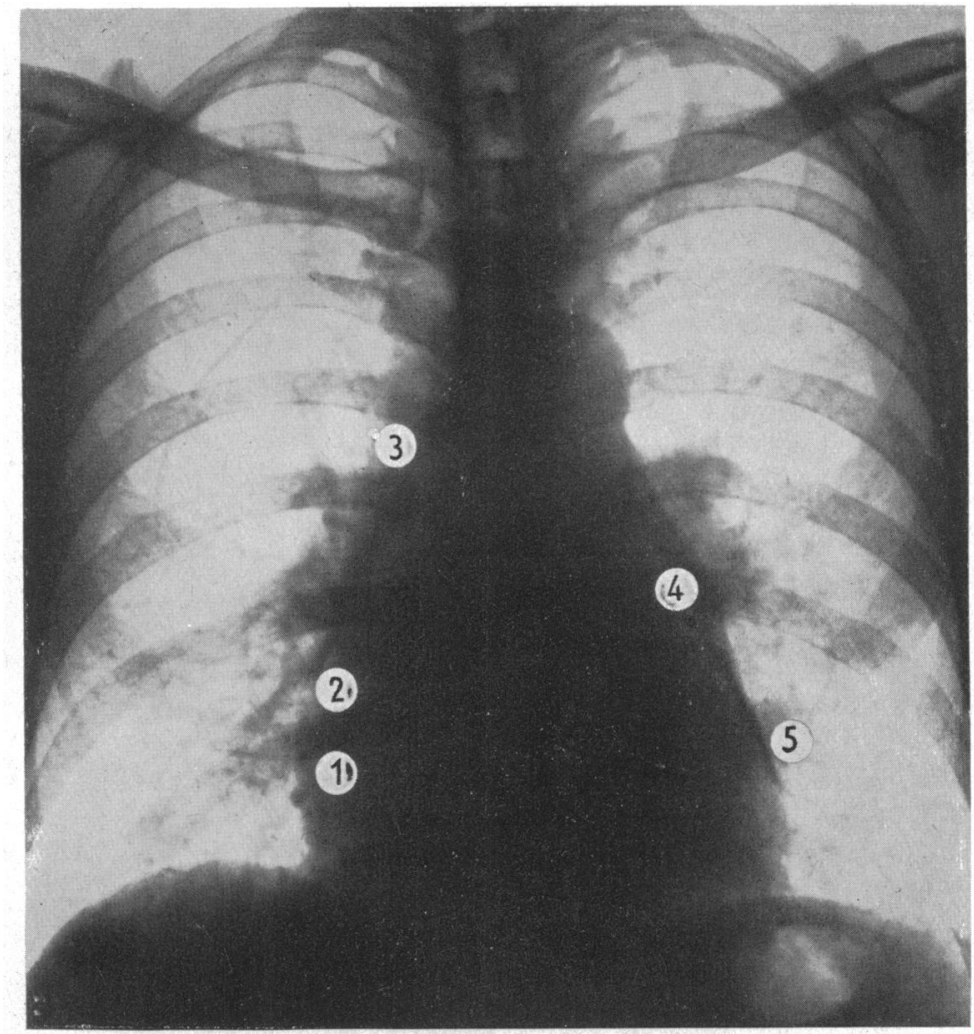

FIG. 12.-Constrictive pericarditis. Silight enlargement of cardiac shadow especially at right auricle (1). Right cardiovascular angle (above 2) filled in. Prominence of superior vena cava (3) and of left cardiac border probably by left auricle (4). There was no mitral valve disease. Strip of calcium (5) at left ventricular border.

Occasionally a completed ring of calcium is seen within the cardiac shadow from calcification in the A-V groove, while in others only scattered or single plaques of calcium are visible.

Changes in the Lungs. In 14 patients the lung fields were clear except for incidental emphysema in one; in the other 16 there were changes in both lungs in 6 and confined to the right in 9 and the left in one. Hydrothorax and pleural thickening, once with calcification, were the common findings, occurring separately or together. The changes suggested the ancillary effects of a tuberculous infection although in cases where the aspirated pleural fluid was examined bacteriologically, the tubercle bacillus could not be found. 


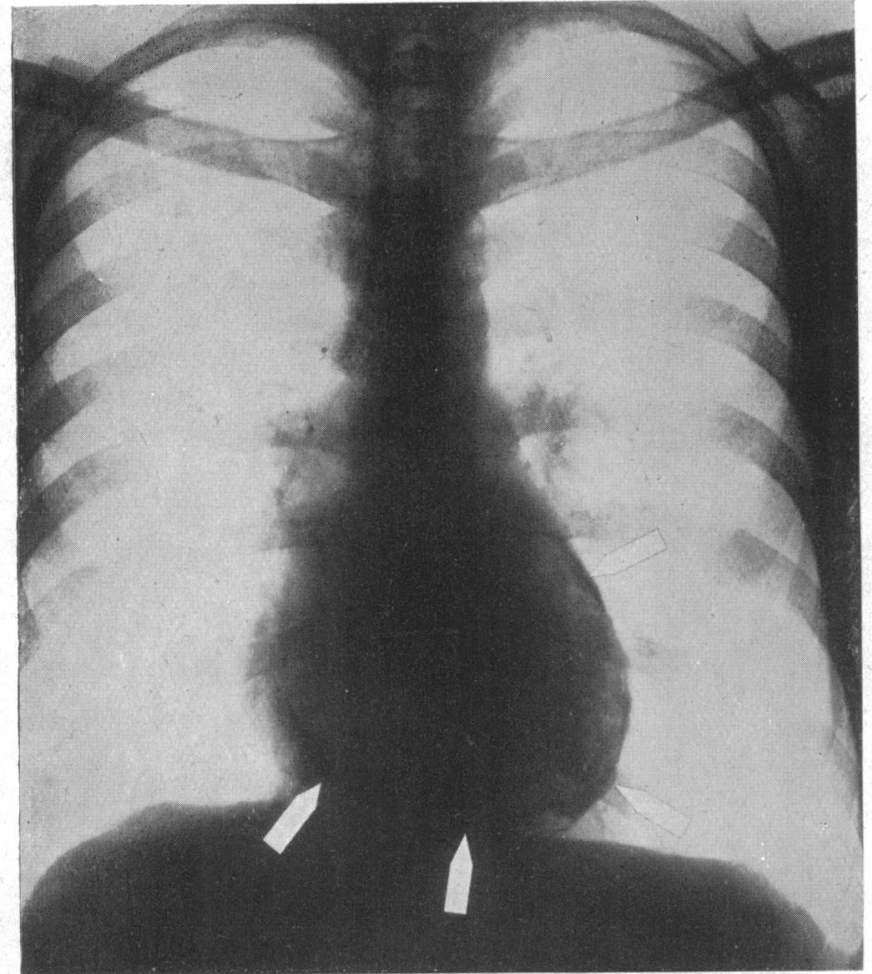

FIG. 13.-Constrictive pericarditis. Heart encased by ring of calcium (arrows) especially prominent at left and inferior borders.

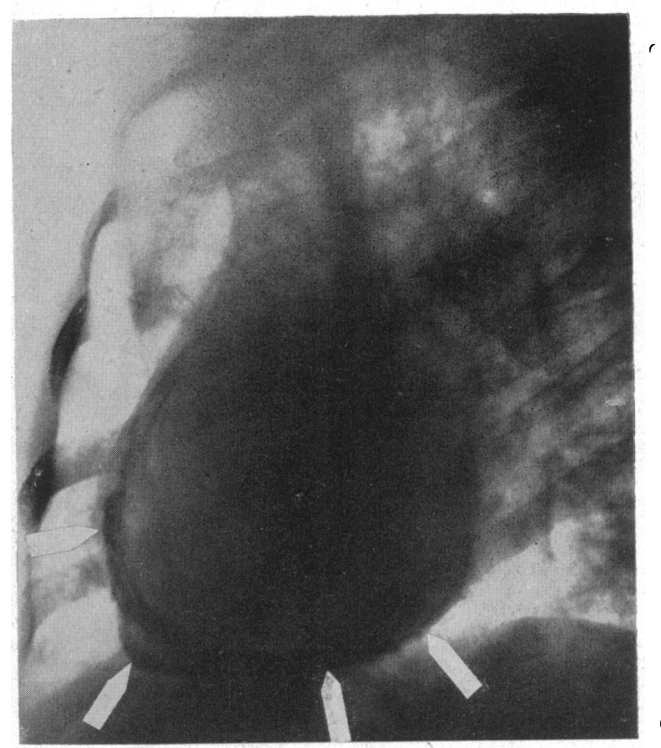

FIG. 14.-Constrictive pericarditis. Left anterior oblique. Heart appears held cup-like by calcified band (arrows).

\section{Liver Biopsy}

Among the 4200 necropsies examined by Koletsky and Barnebee (1944) there were 30 with congestive cirrhosis; constrictive pericarditis was the cause of the cirrhosis in 5 cases. They applied a diagnosis of cirrhosis only when there was alteration in the architectural pattern of the liver in addition to fibrosis. The liver from five patients with constrictive pericarditis showed greater fibrosis and distortion of pattern than did any of the others in their series. Increase of connective tissue was specially prominent in the portal zones together with proliferation of bile ducts. In two of three others where the pericardial condition had been present for a shorter period of 4 to 14 months there was also slight cirrhosis. The morphological distinction between well-developed Laennec and congestive cirrhosis is obvious, but in the early stages the differentiation may be difficult. Central fibrosis only occurs in the congestive form, and even when the fibrosis is chiefly portal in its distribution the congestive type usually shows central hyperæmia with atrophy or necrosis of the parenchyma. Moreover, in congestive cirrhosis the nodules of the liver parenchyma are irregular in shape and join up with one another while those of Laennec cirrhosis tend to be circular, circumscribed, and isolated.

The appreciation of the common incidence of hepatic fibrosis in constrictive pericarditis has the greatest value in determining the prognosis of this condition and predicting the progress anticipated from surgical treatment. A liver biopsy was carried out in seven of our cases. In three the specimen retrieved was inadequate and did not allow opinion on the histological pattern; in three there was fibrosis and in one there was much central congestion without fibrosis. Our experience with liver biopsy obtained either by drilling or by puncture has emphasized the difficulty and the uncertainty of the operation and it is unlikely to become a routine procedure on that account. 


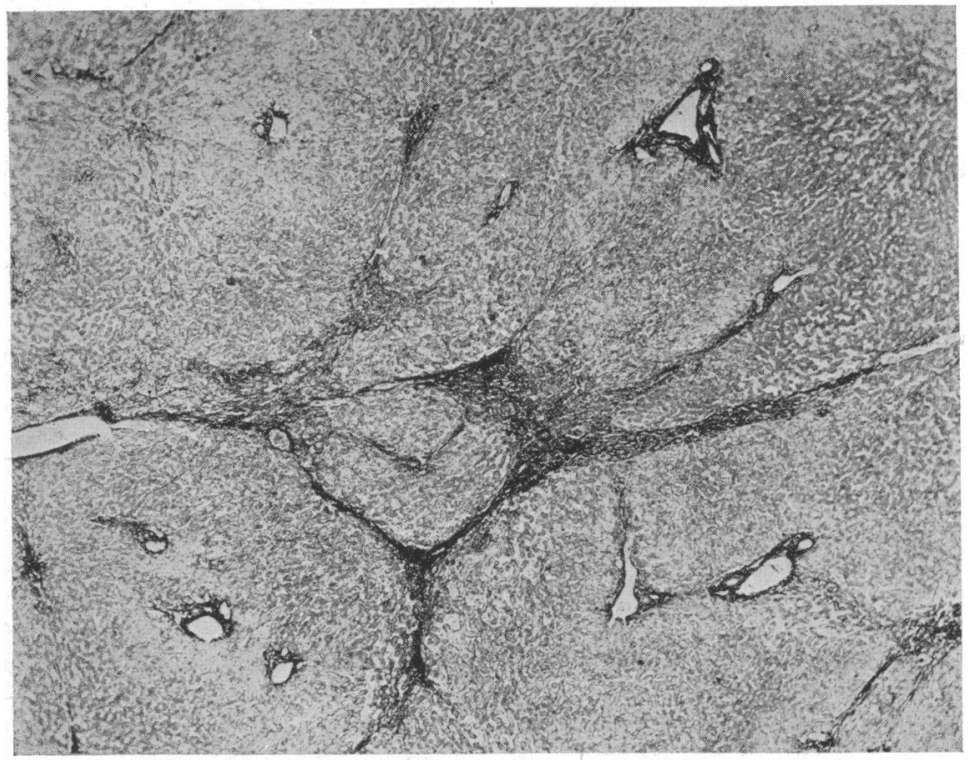

Fig. 15.-Constrictive pericarditis. Early congestive cirrhosis of liver.

FIG. 16.-Constrictive pericarditis. Severe congestive cirrhosis of liver.

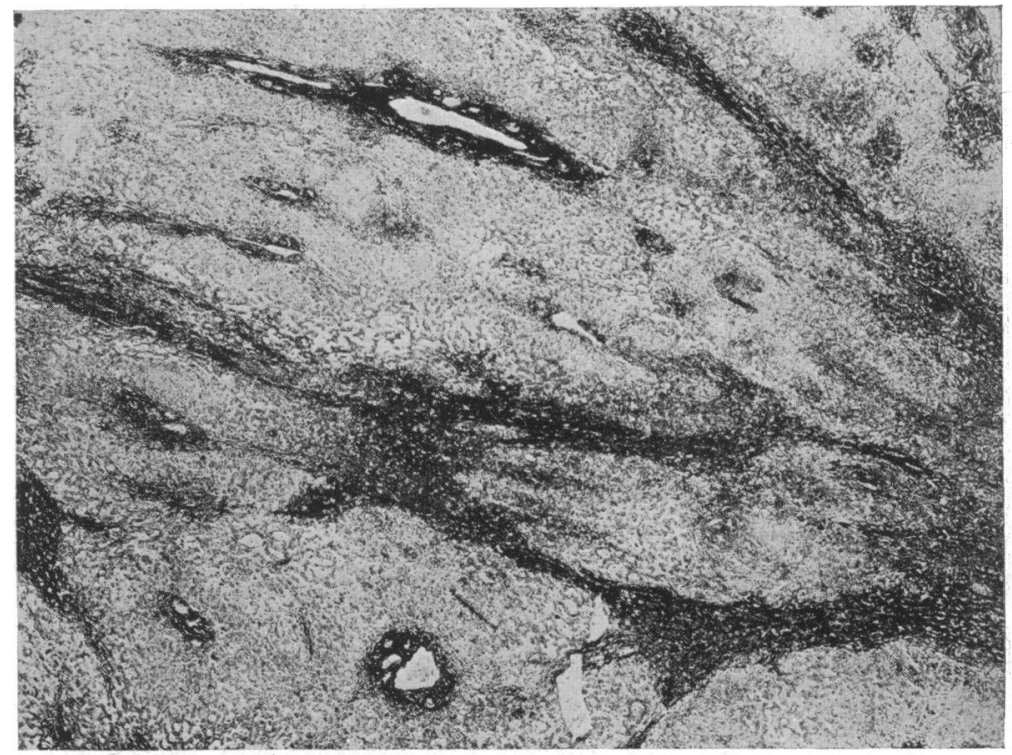

There is hardly need of a liver biopsy in the early cases where the symptoms have lasted less than two years because in these, although hepatic fibrosis is almost invariably present, its severity is not such as to retard recovery after surgical treatment of the pericardium (Fig. 15). In patients where constrictive pericarditis has lasted a longer time a knowledge of the extent of the liver damage is very desirable for it may be so great as to predict failure of the procedure of cardiac decompression as a means of relieving the symptoms, and ascites may persist as the direct outcome of the hepaticfibrosis (Fig. 16). 


\section{PROGRESS}

Twenty-five of our 30 patients are still alive and have been watched since the operation of cardiac decompression for periods of six months to thirteen years; the average period has been four and a half years.

Five patients are dead, one of them from empyema three weeks after operation. Considering that the condition had sometimes been present for many years and the degree of distension of the liver and ascites, the infrequency of early deaths has been regarded as very satisfactory. Two patients who gained no benefit from the operation died, one after four months and the other after two years: in the latter, abdominal paracentesis had to be carried out monthly as before the operation and she ultimately died suddenly from pulmonary embolism; necropsy showed severe congestive cirrhosis of the liver which itself was considered to be the cause of recurring ascites; there was also miliary tuberculosis of the lungs. The fourth patient derived immediate benefit from the operation, but died after a short illness eight months later from meningitis and generally disseminated miliary tuberculosis. The fifth, aged 59, died ten years after the operation which had enabled him to resume his duties actively as an engineer and rescued him from invalidism and confinement to his house that had lasted for two years.

Six of the 25 living patients gained benefit from the operation, but since they continue to have symptoms and need digitalis and mercurial diuretics to overcome fluid-retention, they are counted here among the unsuccessful cases; one of them, however, has mitral stenosis; another improved for four years before the symptoms returned, and a third, although with a limited exercise tolerance, has returned to work in the Post Office after an enforced absenteeism of nine months and indifferent health for five years. One patient who has returned to his work as a window dresser six months after his operation has not been classified because it was considered premature to assess his ultimate prognosis.

The operation of cardiac decompression has removed the symptoms in the remaining 18 so that it has succeeded in 65 per cent of the patients in our series who have already survived for an average period of five years since operation. These patients follow their customary occupations without complaints and a few statements from them illustrate the great relief obtained from surgical treatment. An electrician, aged 61, states five years after the operation, "I can climb 90 stairs without trouble." A lift attendant, aged 50, states two years after the operation, "I have not felt so well for ten years." A clerk, aged 48, states two years after invalidism involving recurrent hydrothorax, ascites, and œdema, "I have never looked back." An electrician's mate, aged 54, states one year after the operation, "I can do anything." A bricklayer, aged 28, states six years after operation, "I can work double union rates for 10 hours a day." The remaining patients who gained satisfactory benefit from cardiac decompression include a schoolboy, a blacksmith's mate, an officer in the military police, a man who served three years at sea during the war, and a girl who has married and borne one child since her operation 11.years ago. Naturally, certain signs remain in some of them, such as distended neck veins, auricular fibrillation, and an abnormal cardiogram, but by themselves these do not prove a handicap.

The value of surgery in the treatment of constrictive pericarditis has been widely proclaimed and our experience supports this favourable view of a procedure which can frequently change a life of helpless invalidism to one of ease and even of usefulness, and often restores sound health. Improvement in anæsthesia and surgical technique has reduced the immediate risks of the operation in recent times, and a comparison of the results obtained in separate published series suggests that favourable results from surgical treatment show an increase in the past decade from about one among two cases to two among three (Table I).

According to Santy et al. (1946) and Mortensen and Warburg (1948) the results are less favourable in older patients and in the presence of calcification, but our experience does not support this view. Thus, the average age of our successful cases at the time of operation was 35 against 31 years for those who did not benefit to the same extent. Similarly, the degree of calcification was the same 
TABLE I

A Comparison of the Results of Cardiac Decompression in Patients with Constrictive Pericarditis REPORTED BY DIFFERENT AUTHORS

\begin{tabular}{|c|c|c|c|c|c|}
\hline Author & & & $\begin{array}{c}\text { Number } \\
\text { of } \\
\text { Cases }\end{array}$ & $\begin{array}{c}\text { Mortality } \\
\text { Rate } \\
\text { (Percentage) }\end{array}$ & $\begin{array}{l}\text { Successful } \\
\text { Results } \\
\text { (Percentage) }\end{array}$ \\
\hline $\begin{array}{l}\text { Sodeman (1941) } \\
\text { Edwards and Barlow (1946) } . . \\
\text { Santy, Berard, and Piquet (1946) } \\
\text { Mortensen and Warburg (1948) } \\
\text { Sellors (1948) .. } \\
\text { Paul, Castleman, and White (1948) }\end{array}$ & $\begin{array}{l}\ddot{ } \\
\ddot{ } \\
\ddot{0} \\
\ddot{.}\end{array}$ & $\begin{array}{ll}\because . & . \\
\because . & . \\
\because . & \cdots \\
\because . & . \\
. . & . .\end{array}$ & $\begin{array}{l}\text { Review } \\
20 \\
20 \\
21 \\
42\end{array}$ & $\begin{array}{c}33 \\
25 \\
\overline{45} \\
19 \\
25 \\
\text { (excluding } 6 \text { deaths } \\
\text { from other disease) } \\
13\end{array}$ & $\begin{array}{l}50 \\
50 \\
50 \\
35 \\
66 \\
60\end{array}$ \\
\hline
\end{tabular}

in each group. In our experience there is one overriding factor that influences the success or otherwise of the surgical treatment of constrictive pericarditis, and it is the extent to which congestive cirrhosis of the liver has already taken place. It is a common event among even the early cases, but when the effects of constrictive pericarditis have been present for some years the liver injury is so great that even when its cause is removed it will by itself prevent recovery from symptoms, especially ascites. Such knowledge should impel , us to diagnose constrictive pericarditis early and to apply surgical treatment before the liver damage has reached an irrecoverable stage.

Preparation for Operation. Cardiac decompression for the relief of symptoms caused by constrictive pericarditis should not be undertaken as an emergency operation and need never be done in a hurry. When the diagnosis has been substantiated there remains the decision to be taken on treatment, and for this purpose the patients belong to one of three groups.

In the first group are those patients who have recently suffered from acute tuberculous pericarditis, usually with pericardial effusion early in the illness, and where the clinical and cardiographic signs of constrictive pericarditis have appeared. A decision has to be taken on the most favourable time to resort to surgery. The period of waiting need not be long, and we think that the operation should take place as soon

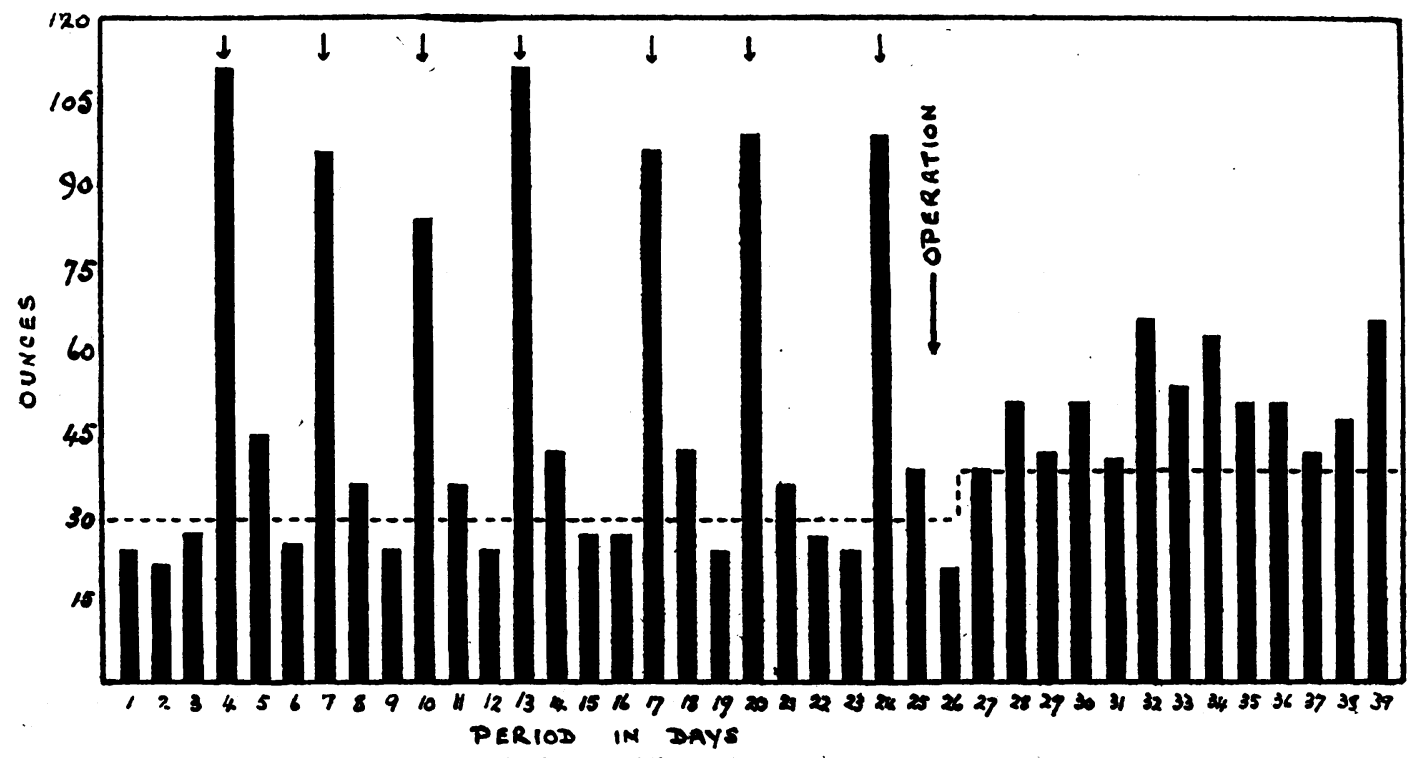

Fig. 17.-Constrictive pericarditis. Fluid intake (discontinuous line) and urinary output (black columns) shown before and after operation of cardiao decompression. Arrows indicate intravenous injections of $2 \mathrm{ml}$. of neptal. 
as it has been shown that the urinary output is never equal to the measured fluid intake, and that the use of mercurial diuretics is needed to prevent fluid retention, this usually showing as ascites (Fig. 17). We favour operating early in such cases and think that surgical treatment should take place even when the symptoms are objective in kind in the belief that subjective symptoms are inevitable later and that their absence need not delay the operation.

Belonging to the second group are those cases showing evidence of tuberculosis in places other than the pericardium. A decision on surgical treatment in such cases is always difficult, but it should never be precipitate and adequate time should be devoted to conservative treatment. If tuberculosis shows in a joint like a knee or elbow, as adenopathy in the neck, as fibrosis or cavitation or miliary nodules in the lungs, in addition to the pericardial lesion, a state of partial hæmatogenous dissemination may be presumed to have taken place, and months should be allowed to elapse before releasing the heart by piece-meal removal of the thick pericardium that encases it. Indeed, the wisdom of waiting may find proof in the rapid extension of tuberculosis and the demise of the patient during this period of observation. Such instances are uncommon, but we have met with three.

The third group includes patients in whom the condition has been present for some time, often for two or more years. In these cases a liver biopsy is helpful; should it show conspicuous congestive cirrhosis, surgery is unlikely to bring benefit, for the ascites is likely to persist after relief of the pericardial condition. Should liver biopsy prove favourable and a decision be made to operate the patient should be rested in hospital for four weeks on fluid and salt restriction, with digitalis, and weekly injections of a mercurial diuretic; if ascites is a prominant sign it should be dealt with initially by paracentesis. The aim is to bring the patient to the operating table free from pleural effusion, ascites, and œdema. In these instances especially, a quiet persistence in sound medical treatment should never yield to the impatience that is inseperable from the anticipation of the more spectacular results of surgery.

\section{SumMaRY 'AND CONCLUSIONS}

Our experience with 30 cases of constrictive pericarditis that received surgical treatment has allowed us to draw the following conclusions.

The condition is caused by tuberculosis, and generally the infection is confined to the pericardium apart from an innocuous involvement of the pleura; its presence elsewhere should delay surgical interference.

Constrictive pericarditis, characterized by great thickness, often with caseous changes at its centre and frequently showing calcification, differs from the flimsy adherent pericardium that is a common and incidental finding at necropsy.

Although breathlessness on exertion is common it does not tally altogether with the dyspnœa of heart failure in that halting gives instant relief and there is never pulmonary congestion; we have thought it should be designated differently and suggest for it the term restricted ambulation. When the diaphragm is raised significantly through the presence of great ascites, respiration becomes embarrassed even at rest.

Two-thirds of the patients complained of fulness or swelling of the abdomen and as many of swelling of the ankles. The pulse was usually small, and the blood pressure, which was not once raised, was often low. Auricular fibrillation was present in more than one-third of the cases, when the ventricular rate proved to be relatively slow even in the absence of digitalis.

An adventitious heart sound was heard along a line joining the mitral area to the xiphisternum in 27 out of 30 patients; in 17 it came from splitting of the second heart sound, and in 10 it was in the form of triple rhythm from the addition of the third heart sound. A diligent search for these auscultatory signs is essential for an examination that tests the presence of constrictive pericarditis, because their absence almost excludes the diagnosis. Disappearance of the signs after a successful operation was common and itself predicted a favourable outlook.

Cyanosis was not found early in the illness, but full neck veins were always present; so also was distension of the liver: if these two signs are absent the diagnosis of constrictive pericarditis should not be entertained. 
Absence of crepitations over the lung bases, of pulmonary congestion at cardioscopy, of much cardiac enlargement, and of significant heart murmurs, in the presence of preponderant ascites over œdema, are signs that help to distinguish constrictive pericarditis from failure of the right heart due to any cause including valvular disease.

The electrocardiogram often showed auricular fibrillation, but its particular characteristic was a deformity of the $T$ wave, and also of the $P$ wave in those without fibrillation. Thus, the form of the $P$ wave was altered in all save two cases, and this consisted of notching where the second peak was usually taller than the first, producing a step or shelf; this change supported the cardiographic diagnosis of constrictive pericarditis in the less common cases where characteristic deformity of the $\mathrm{T}$ wave was inconspicuous. A low, flat, or inverted T wave was present in all patients with one exception; in 19 the changes were very noticeable, and in 10 out of 11 where the $T$ wave deformity was less noticeable, the work of peeling the pericardium from the heart proved a relatively easy task com: pared with the laborious stripping in those with deep inversion of the $T$ wave, for in these the pericardial inflammatory process penetrated into the myocardium. The distribution of $\mathrm{T}$ wave changes depended on the area affected by the pericardial condition. Thus, the $T$ was inverted in leads II, III, and CR7, or in these and in CR4, while sometimes inversion of T wave in lead I was added to such changes. Exaggerated $Q$ waves were never seen so that a significant $Q$ accompanying a deformed $\mathrm{T}$ wave should be identified with myocardial rather than pericardial disease.

Radiology of the heart proved an indispensible corroborative test in the diagnosis of the pericardial condition, and some or all of the following changes were found in our 30 cases: slight or moderate enlargement of the cardiac silhouette, prominence of the right border, filling of the cardiovascular angle on the right side, calcification, absence of pulmonary congestion, and prominence of the left auricular impression in the right oblique with barium in the esophagus; this last change differed from that met with in mitral stenosis in that between the barium stream and the heart shadow there was a relatively clear area. Calcification of the pericardium was present in twothirds of our cases; this sign, so valuable in diagnosis, need never evade careful cardioscopy if it is sought in three special places: in the anterior view it is seen end-on as a strip along the left ventricular border and/or mesially below the heart which it appears to support saucer-like; in the left anterior oblique view the calcium line shows even to better advantage and may be likened to an eggcup holding the heart.

The common incidence of congestive cirrhosis in constrictive pericarditis lends importance to an examination by liver biopsy, but the procedure is difficult and the uncertainty of gaining sufficient material opposes its routine use. It is of value, however, in long-standing cases with great hepatic enlargement and ascites, because it should help in such cases to decide whether the hepatic fibrosis is severe enough to maintain ascites even when the pericardial effect is removed at operation.

Treatment by cardiac decompression where the heart, particularly both ventricles, was denuded of the thick pericardium brought relief to most of our patients and especially when the condition was dealt with early and before cirrhosis had so developed as to produce its own effects. For this reason, an earlier recognition of constrictive pericarditis should be our constant aim, for in the absence of surgical treatment it progresses tardily but inexorably towards hopeless invalidism, and beyond the aid of any form of therapy.

The operation of cardiac decompression in our earlier cases was carried out by the late Mr. A. Tudor Edwards, and in our more recent cases by Mr. Vernon Thompson who has generously placed his notes of the cases at our disposal. Three patients were under the care of Sir John Parkinson, one under Professor Clifford Wilson, one under Dr. Lloyd Rusby, and another under Dr. R. R. Bomford. The material removed at operation, and at necropsy in five instances, was examined by either Professor Hubert M. Turnbull, Professor D. Russell, Dr. W. W. W oods, or Dr. J. R. Gilmour, at the Bernhard Baron Institute of Pathology.

\section{REFERENCES}

Armstrong, T. G. (1940). Lancet, 2, 475.

Andrews, G. W. S., Pickering, G. W., and Sellors, T. H. (1948), Quar. J. Med., 17, 291.

Edwards, A. T., and Barlow, D. (1946). J. Internat. Chir., 6, 15. 
Evans, W. (1943). Brit. Heart J., 5, 205.

(1945). Brit. Heart J., 7, 215.

Harrison, M. B., and White, P.D. (1942). Ann. intern. Med., 17, 790.

Jackson, F. (1950). Proc. roy. Soc. Med., 43, 311.

Kerley, P. (1948). Proc. roy. Soc. Med., 41, 437.

Koletsky, B., and Barnebee, J. H. (1944). Amer. J. med. Sci., 207, 421.

Leatham, A., and Towers, M. (1951). Personal Communication.

Mortensen, V., and Warburg, E. (1948). Acta. med. scand., 131, 203.

Parkinson, J. (1936). Lancet, 1, 1341.

Parsons-Smith, B. T. (1948). Proc. roy. Soc. Med., 41, 431.

Paul, O., Castleman, B., and White, P. D. (1948). Amer. J. med. Sci., 216, 361.

Santy, P., Berard, M., and Piquet, G. (1946). J. Internat. Chir., 6, 38.

Sellors, T. H. (1948). Proc. roy. Soc. Med., 41, 435.

Sodeman, W. W. (1941). Amer. J. med. Sci., 202, 127.

Volhard, F. and Schmieden, V. (1923). Klin. Wochenschi, $2,5$.

White, P. D. (1935). Lancet, 2, 539 and 597. 